\title{
SECTION 3
}

\section{SUPPRESSED PULMONARY EXPRESSION OF LEPTIN IN LIPOPOLYSACCHARIDE-INDUCED ACUTE AND CHRONIC LUNG INFLAMMATION}

J.H.J. Vernooy, R.H.E. Cloots, M.A. Dentener and E.F.M. Wouters

University Hospital Maastricht, Maastricht, The Netherlands

WINNING ABSTRACT: Leptin, originally described as an adipocyte-derived hormone regulating energy expenditure, is now classified as a type I cytokine. We and others recently demonstrated that the lung is an additional source of leptin. The aim of the present study was to investigate the effect of acute and chronic inflammation on pulmonary expression of leptin in male Swiss mice. Acute lung inflammation was induced by a single intratracheal (IT) dose of $5 \mu \mathrm{g}$ LPS (E.coli O55:B5), and mice were killed $4 \mathrm{~h}, 24 \mathrm{~h}$ and $72 \mathrm{~h}$ postexposure. Chronic lung inflammation was induced by repeated LPS exposure (twice a week for 12 wks) and mice were killed after a 1-wk or 8-wks recovery period. Lungs were removed to assess cellular influx, leptin protein (immunohistochemistry) and mRNA (RT-PCR). Acute LPS exposure induced a transient neutrophilia (Vernooy, J. et al. AJRCMB 2001; 24:569-576). Chronic LPS exposure resulted in persistent accumulation of macrophages and CD8+ T-cells and emphysema (Vernooy, J. et al. AJRCMB 2002; 26:152-159). Control mice displayed positive leptin staining in bronchiolar epithelium and alveolar macrophages. Both acute $(4 \mathrm{~h}, 24 \mathrm{~h}, 72 \mathrm{~h})$ and chronic (1-wk) inflammation was associated with complete suppression of pulmonary leptin expression at protein and mRNA level. Leptin expression was fully restored after 8-wks of recovery. Lungs of mice displayed constitutive leptin expression in bronchiolar epithelium and alveolar macrophages. Acute and chronic lung inflammation resulted in complete suppression of pulmonary leptin expression. Our data suggest that downregulation of leptin expression in lung may contribute to chronic pulmonary inflammation.

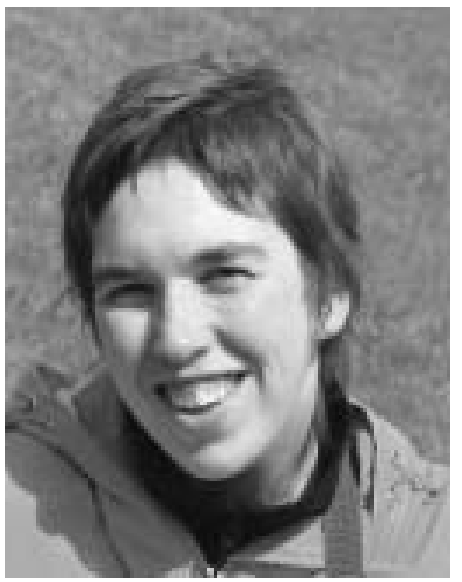

Juanita H.J. Vernooy

Dept of Respiratory Medicine, University Hospital Maastricht, Maastricht, The Netherlands

\section{MY JOB AND THE UNIT IN WHICH I WORK}

I am working as a postdoctoral fellow at the Dept of Respiratory Medicine (Head: Prof. Dr E.F.M. Wouters) at the University Hospital Maastricht/Maastricht University, located in Maastricht in the south-eastern part of the Netherlands. Due to the mining industry in the past, this area was confronted with a high prevalence of coal miners and related chronic respiratory diseases. Since the foundation of our department in 1980, research activities have been oriented towards chronic respiratory diseases and chronic obstructive pulmonary disease (COPD) in particular. However, this decision was less evident then than it would be now: the burden of COPD at that time was still unrecognised and the scientific field was mainly focused on asthma research. Furthermore, the targeted approach of the Maastricht group was considered quite remarkable: nutritional and metabolic aspects in the pathogenesis of COPD. At present, partly based on the research activities in Maastricht, muscle wasting and related metabolic disturbances are considered an integrated part in the systemic work-up of the disabled COPD patient, since they contribute to increased morbidity and mortality. The present research in our group is embedded in the research school at the Nutrition and Toxicology Research Institute Maastricht (NUTRIM; scientific director: Prof. Dr A.M.W.J. Schols), and focuses on unravelling disease-specific respiratory and muscular modifications in stable disease, as well as during episodes of acute exacerbations, presently the most important component of the economic burden of COPD. Very important in this respect is the collaboration with CIRO Horn, a leading third-line centre for in-patient pulmonary rehabilitation in the Netherlands. Furthermore, structured research collaboration with $\mathrm{Dr}$ Y.M.W. Janssen-Heininger from the Dept of Pathology at the University of Vermont (Burlington, VT, USA) created unique facilities to extend our work in the fields of molecular and cell biology. Our department runs a website, www.pul.unimaas.nl, that gives information about our research topics and provides links to all publications and theses.

\section{MY WINNING ABSTRACT AS PART OF MY RESEARCH}

My PhD project was entitled "Characterization of inflammation in COPD: clinical and experimental approach", and was a structured research collaboration between the Depts of Respiratory Medicine and General Surgery (Prof. Dr 
W.A. Buurman) at the Maastricht University. During this period, I analysed mediators of innate immunity (leptin, cytokines and soluble receptors, chemokines, acute-phase proteins and proteinases) in induced sputum and plasma of COPD patients and controls, and assessed their localisation in lung resection tissue [1-3]. In parallel, I studied the pulmonary and systemic innate immune response in a mouse model of acute pulmonary inflammation induced by single intratracheal instillation of bacterial lipopolysaccharide $[4,5]$. Furthermore, I used this model to develop a model of chronic inflammation (repeated instillations), which displays a chronic pulmonary and systemic inflammation accompanied by COPD-like pathological alterations [6].

My current research project is entitled "Leptin, a pivotal mediator in innate immunity in lung?" This project started in March 2006 and is funded by a personal grant from the Netherlands Asthma Foundation. Leptin was originally described as an adipocyte-derived hormone involved in food intake and energy expenditure. However, recent studies indicate that other organs, including the lung, can express leptin under specific circumstances. Leptin is now classified as a type I cytokine and considered to be an important link between innate and adaptive immune processes. In order to study the cellular and molecular aspects of leptin-mediated processes in the lung, I will use a mixture of: 1) in vitro mechanistic experiments in well-established (primary) cell cultures; and 2) in vivo disease models of acute and chronic lung inflammation combined with (conditional) models of leptin deficiency. My winning abstract and my other presentation at the European Respiratory Society Annual Congress 2006 entitled "Leptin activates the JAK/STAT signalling pathway in bronchial and alveolar epithelial cells" [7], are the first outputs of this project and serve as a basis to further explore the function of leptin in the respiratory system.

\section{MY RESEARCH AS PART OF MY WORKING GROUP/ RESEARCH TEAM}

My research line is well embedded in the main research area of our department. As a postdoctoral fellow, I am part of the Respiratory Biology team from the Dept of Respiratory Medicine lead by Prof. E.F.M. Wouters, which currently comprises two further postdoctoral fellows (Mieke Dentener and Niki Reynaert). Our research is directed towards the understanding of chronic inflammatory processes, especially the link between chronic inflammation and pathology in COPD, the mechanism of chronicity of inflammatory processes and the origin of systemic inflammation in COPD. To this end, we use in vitro cell culture systems, several in vivo disease models and patients' materials.

\section{THE IMPACT OF MY WORK ON CLINICAL OR RESEARCH PRACTICE}

A causal link between long-term exposure to cigarette smoke, particulate matter and other environmental substances and development and/or exacerbation of major lung disorders, such as COPD, asthma and lung cancer, is well established. As the regulating mechanisms are incompletely understood, there is an urgent need to elucidate these pathways. Basic knowledge of chronic inflammatory processes, and leptin action in particular, will allow us to identify novel therapeutic targets as well as strategies to restore immune homeostasis in acute and chronic inflammatory lung disorders.

The common future goal of the Maastricht group is to facilitate and support multidisciplinary organised respiratory research in a creative environment, in order to upgrade respiratory care and to improve health status and quality of life for the patient, and to attenuate the burden of these diseases for the next generations.

\section{REFERENCES}

1 Vernooy JH, Kucukaycan M, Jacobs JA, et al. Local and systemic inflammation in patients with chronic obstructive pulmonary disease: soluble tumor necrosis factor receptors are increased in sputum. Am J Respir Crit Care Med 2002; 166: 1218-1224.

2 Broekhuizen R, Vernooy JH, Schols AM, Dentener MA, Wouters EF. Leptin as local inflammatory marker in COPD. Respir Med 2005; 99: 70-74.

3 Vernooy JH, Lindeman JH, Jacobs JA, Hanemaaijer R, Wouters EF. Increased activity of matrix metalloproteinase8 and matrix metalloproteinase- 9 in induced sputum from patients with COPD. Chest 2004; 126: 1802-1810.

4 Vernooy JH, Dentener MA, van Suylen RJ, Buurman WA, Wouters EF. Intratracheal instillation of lipopolysaccharide in mice induces apoptosis in bronchial epithelial cells: no role for tumor necrosis factor- $\alpha$ and infiltrating neutrophils. Am J Respir Cell Mol Biol 2001; 24: 569-576.

5 Vernooy JH, Reynaert N, Wolfs TG, et al. Rapid pulmonary expression of acute-phase reactants after local lipopolysaccharide exposure in mice is followed by an interleukin-6 mediated systemic acute-phase response. Exp Lung Res 2005; 31: 855-871.

6 Vernooy JH, Dentener MA, van Suylen RJ, Buurman WA, Wouters EF. Long-term intratracheal lipopolysaccharide exposure in mice results in chronic lung inflammation and persistent pathology. Am J Respir Cell Mol Biol 2002; 26: 152-159.

7 Vernooy JHJ, Haegens A, Van Opbergen D, Cloots RHE, Wouters EFM. Leptin activates the JAK/STAT signaling pathway in bronchial and alveolar epithelial cells. Eur Respir J 2006; 28: Suppl. 50, S338. 